\title{
Compreendendo o significado da liderança para o aluno de graduação em enfermagem: uma abordagem fenomenológica
}

\author{
Understanding the meaning of leadership to the undergraduate nursing student: \\ a phenomenological approach \\ Comprendiendo el significado del liderazgo para el alumno de graduación en enfermería: \\ un enfoque fenomenológico
}

\section{Karina Juliana Guerra', Wilza Carla Spiri"}

' Universidade de São Paulo, Escola de Enfermagem, Programa de Pós-Graduação em Enfermagem (Doutoranda). São Paulo-SP, Brasil.

"Universidade Estadual Paulista "Júlio de Mesquita Filho", Faculdade de Medicina de Botucatu, Departamento de Enfermagem. Botucatu-SP, Brasil.

\author{
Submissão: 24-02-2012 Aprovação: 20-05-2013
}

\section{RESUMO}

O objetivo do estudo é compreender o significado da liderança para o graduando em enfermagem e a expectativa relacionada à sua prática profissional. Utilizou-se o referencial da fenomenologia. Quinze graduandos em enfermagem foram sujeitos e responderam a questão: Qual a compreensão que você tem sobre liderança e como espera aplicá-la em sua prática profissional? Os temas revelados analisados, Estilos de Liderança e Exercício da Liderança, nos permitiram compreender que o significado atribuído à liderança é desvelado como um processo dinâmico e o estilo adotado é a forma de conduzir uma equipe, não existindo um estilo ideal de liderança. No ensino, o estilo de liderança passou a ser discutido quando abordou as formas participativas de gerenciamento de pessoal. No Exercício da Liderança, é enfatizada a dissociação da teoria e da prática da liderança, destacando-se que a integração com a prática é relevante para a aprendizagem da liderança.

Descritores: Liderança; Educação em Enfermagem; Pesquisa Qualitativa.

\section{ABSTRACT}

This study aimed at understanding the meaning of leadership to undergraduate nursing students and the expectation related to their professional practice. Phenomenology was used as theoretical framework. Fifteen undergraduate nursing students were recruited as subjects and answered the following question: "What do you understand by leadership, and how can it be applied in your professional practice?" The topics which were revealed and analyzed, Leadership Styles and Leadership Exercise, enabled us to understand that the meaning attributed to leadership is unveiled as a dynamic process, and the style adopted is the form to lead a team; therefore, an ideal leadership style does not exist. In teaching, the leadership style began to be discussed when the participant forms of personnel management were approached. In leadership practice, the dissociation between leadership theory and practice is emphasized, pointing out that integration with practice is relevant for leadership learning.

Key words: Leadership; Nursing Education; Qualitative Research.

\section{RESUMEN}

El objetivo de este estudio es comprender el significado del liderazgo para el graduando en enfermería y la expectativa relacionada a su práctica profesional. Se utilizó el referencial de la fenomenología. Quince graduandos en enfermería fueron los sujetos que respondieron a la cuestión: ¿Cuál la comprensión que tiene usted sobre liderazgo y cómo espera aplicarlo en su práctica profesional? Los temas revelados analizados, Estilos de Liderazgo y Ejercicio del Liderazgo, nos permitieron comprender que el significado atribuido al liderazgo es desvelado como un proceso dinámico, el estilo adoptado es la forma de conducir un equipo y no existe un estilo ideal de liderazgo. En la enseñanza, el estilo de liderazgo pasó a ser discutido cuando enfocó las formas participativas de manejo de personal. En el Ejercicio del Liderazgo, es enfatizada la disociación de la teoría y de la práctica del liderazgo, destacándose que la integración con la práctica es relevante para el aprendizaje del liderazgo.

Palabras clave: Liderazgo; Educación en Enfermería; Investigación Cualitativa. 


\section{INTRODUÇÃO}

Durante minha experiência profissional como enfermeira pude observar que há um distanciamento entre a teoria e a prática da enfermagem levando o enfermeiro a desenvolver seu processo de trabalho centrado no modelo gerencial hegemônico, que privilegia o modelo funcional e que muitas vezes afasta o enfermeiro de seu objeto de trabalho.

Esse perfil de enfermeiro não atende as suas próprias aspirações pessoais e profissionais, gerando insatisfações e frustrações.

No trabalho em equipe multiprofissional o enfermeiro deverá assumir posição de liderança. A liderança envolve compromisso, responsabilidade, empatia, habilidade para tomada de decisões, comunicação e gerenciamento de forma eficaz.

Diante disso, acredito que seja necessário um repensar sobre a prática de enfermagem e sobre a formação dos futuros enfermeiros, a fim de impulsionar mudanças na assistência, nas relações de trabalho e no gerenciamento.

Atualmente, atuando como docente, passei a refletir a importância que a Educação Superior tem em formar profissionais competentes no exercício da liderança, sendo fundamental a preocupação com este aspecto.

Creio ser necessário que os órgãos formadores se sensibilizem e efetivem um processo ensino-aprendizagem no qual possibilitem o desenvolvimento de habilidades próprias da função de líder, oferecendo oportunidades de vivenciar situações práticas de exercício de liderança.

Hoje, liderança pode ser definida como um fenômeno tipicamente social, que ocorre exclusivamente em grupos sociais. Pode-se definir como uma influência interpessoal exercida numa dada situação e dirigida através do processo de comunicação humana para a consecução de um ou mais objetivos



A enfermagem está passando por um processo de repensar e de redefinição de funções, de maneira a assegurar seu papel e seu compromisso com a sociedade, que nesse momento aspira maior qualidade na prestação da assistência à saúde ${ }^{(2)}$.

É necessário desmistificar o gerenciamento de enfermagem como uma disfunção, é importante ao enfermeiro se apropriar desse espaço como um processo de trabalho no contexto da produção em saúde ${ }^{(3)}$.

Nos requisitos básicos para atuação dos enfermeiros, evidencia que eles precisam ter capacidade de liderança e saber trabalhar em equipe. Essa é uma demonstração de que o mercado de trabalho está solicitando do enfermeiro o conhecimento e a aplicação das habilidades de liderança ${ }^{(4)}$.

Dentre as habilidades de liderança exigidas destaca-se: conhecimento, experiência, confiança, capacidade de trabalhar em equipe, de resolver problemas, autodesenvolvimento, relacionamento interpessoal, comprometimento e respeito entre a equipe e saber ouvir( ${ }^{(4)}$.

O perfil de profissional exigido requer habilidades cognitivas (saber) e operacionais (saber fazer), sustentadas pela ética e comprometimento (saber ser). A construção, a gestão dos processos e a formação de sujeitos é um grande desafio ${ }^{(3)}$.

Este perfil exigido pode ser observado nas novas políticas da educação, formulando as diretrizes para formação humana no país, nos níveis de ensino básico, médio e superior.

O curso de graduação deve possibilitar ao futuro enfermeiro, sua instrumentalização para a intervenção na realidade, favorecendo a organização/reorganização do trabalho.

Sendo assim, promover o desenvolvimento das habilidades da liderança durante o processo de formação do enfermeiro tornou-se um desafio a ser vencido pelo aluno e pela academia evitando-se muitos dos problemas que os enfermeiros experienciam em seu trabalho que resultam do processo educacional.

O grande desafio consiste em que as escolas consigam aproximar a formação de enfermagem das inovações decorrentes das diretrizes de maneira a qualificar o enfermeiro para atuar com competência no atual contexto político-econômico e cultural do país(5).

O ensino da Administração em Enfermagem, no que diz respeito às novas propostas do Ministério da Educação, deverá proporcionar ao educando o desenvolvimento de competências e habilidades, a fim de que este, quando for profissional, esteja apto para o exercício do processo de trabalho gerencial, que tem como meios e instrumentos a força de trabalho, os recursos físicos e materiais e o saber administrativo. De modo geral, espera-se que os enfermeiros estejam aptos a serem gestores e líderes na equipe de saúde ${ }^{(6)}$.

Portanto, tenho como indagação: Qual a compreensão que o aluno da graduação em enfermagem tem do ensino da liderança e qual a expectativa deste conhecimento para a sua prática profissional?

\section{OBJETIVO}

Compreender o significado da liderança para o graduando em Enfermagem e a expectativa relacionada à sua prática profissional.

\section{TRAJETÓRIA METODOLÓGICA}

Considero que a compreensão de significados dos sujeitos que vivenciam diferentes situações é mais bem apreendida em abordagens qualitativas de pesquisa e portanto, neste estudo busquei como vertente metodológica a fenomenologia.

O caminho utilizado na pesquisa envolve três momentos: a descrição, a redução e a compreensão fenomenológica.

A descrição fenomenológica possui três elementos: a percepção, a consciência e o sujeito. Busquei os depoimentos, para captar a percepção dos sujeitos do estudo da significação produzida pela consciência para a compreensão da liderança na formação do enfermeiro e a expectativa desta ação na prática profissional.

A redução fenomenológica acontece após a leitura e releituras dos discursos, com o objetivo de selecionar as partes do discurso que são essenciais para desvelar o fenômeno, experiências que são parte da consciência do sujeito para chegar à essência. Com os depoimentos coletados e transcritos, realizou-se a redução, refletindo sobre as falas, extraindo delas sua essência. 
A compreensão fenomenológica é uma investigação das experiências, é uma forma de interpretação. Com a essência e a fala dos sujeitos os temas foram revelados, organizados e interpretados, realizando uma síntese das unidades significativas encontradas e suas convergências, divergências e idiossincrasias, relacionando com o referencial teórico de liderança em enfermagem e formação para liderança em enfermagem.

Foi escolhido para o cenário do estudo, o curso de Enfermagem pertencente a uma Universidade Filantrópica do Interior de São Paulo.

Os sujeitos da pesquisa foram alunos que cursavam o sétimo termo de curso de Graduação em Enfermagem que já haviam realizado a disciplina de administração aplicada à enfermagem.

Os sujeitos do estudo caracterizam-se por serem provindos de escolas publicas, alguns exercerem a profissão de auxiliar ou técnico de enfermagem, e outros que necessitam trabalhar locais diversificados para poderem custear o curso de graduação em enfermagem recebendo bolsa - auxilio para pagamento das mensalidades.

O número de sujeitos considerados como sujeitos da pesquisa, foi definido no decorrer do estudo, a partir das descrições obtidas nos depoimentos e suficientes para responder a interrogação proposta, perfazendo um total de 15 alunos.

Os depoimentos foram numerados de I a XV, analisados individualmente (análise idiográfica) e posteriormente analisados globalmente (análise nomotética). Nos discursos as unidades de significado foram mantidas em negrito e numeradas em numeral arábico, na seqüência em que apareciam. Posteriormente estas unidades foram reduzidas fenomenologicamente e interpretadas para estruturar o fenômeno resgatando assim, sua essência.

O presente estudo foi aprovado pelo Comitê de Ética em Pesquisa (of.215/2006). As entrevistas foram realizadas utilizando-se gravação digital, os sujeitos foram informados antes da entrevista, o propósito do estudo, a dinâmica da entrevista, a garantia do anonimato e sobre a destruição do conteúdo digital gravado após a transcrição das falas. Todos os participantes autorizaram a gravação da entrevista e a participação na pesquisa por meio da assinatura no Termo de Consentimento Livre Esclarecido.

Foi adotada a seguinte questão norteadora: Qual a compreensão que você tem sobre Liderança e como você espera aplicá-la em sua prática profissional? Neste artigo fez-se um recorte do fenômeno revelado e serão apresentados dois temas: Estilos de Liderança e Exercício da Liderança.

\section{RESULTADOS E DISCUSÃO}

O tema, Estilos de Liderança, diz respeito às diferentes formas que os alunos vêm à atuação do líder. As unidades significativas foram resgatadas de momentos que os alunos observaram a enfermeira principalmente no campo de estágio curricular, atuando como líder da equipe de enfermagem, e interagindo de diferentes formas com os liderados, no cotidiano da administração da assistência de enfermagem. São elas: autoritária, democrática e contingêncial.
Assim, as falas desvelam a Liderança como um processo dinâmico, onde o enfermeiro líder de uma equipe muda de estilo frente a diferentes situações. As mudanças ocorrem no sentido de uma liderança democrática para autocrática. $\mathrm{O}$ estilo de liderança democrática não é possível ser sempre adotado, às vezes, é necessário ser autocrático.

[...] O enfermeiro tem que determinar certas funções para os auxiliares técnicos [...] e vai supervisionar o que eles [...] estão fazendo [...] (III-2).

\section{[...] Existem vários tipos de lideres [...] (VII-1).}

[...] o líder tem que ter momentos com pulso firme, mas tem que ser flexível [...] (VIII-2).

Corroborando com este aspecto, deve ser considerada a corporalidade, temporalidade e espacialidade do ser que lidera, e é resgatado no ensino, pela influência de propostas político-sociais das sociedades que em diferentes momentos, têm indicado a direção de um estilo autocrático para uma liderança mais participativa ${ }^{(7)}$.

No ensino, as contradições dos diferentes estilos de liderança são explicadas pelos pressupostos da Teoria Contingencial de Liderança que propõe o comportamento adaptativo do líder e a adoção de diferentes estilos de liderar segundo as expectativas dos liderados, da organização e segundo as características da situação, naquele momento ${ }^{(7)}$.

$\mathrm{O}$ acadêmico de enfermagem pondera que o enfermeiro recém-formado tende a assumir um estilo de liderança autocrático impondo-se e ditando regras, o que em sua visão, não é adequada.

[...] não basta à enfermeira chegar e se impor aos funcionários [...] muitas vezes a enfermeira recém formada, chega ao primeiro dia de trabalho e se impõe colocando pose, eu sou a chefe eu que mando [...] De forma autoritária (II-3)

Uma das principais diferenças que o principiante sente ao assumir o novo papel, é que ele se vê em situações tendo que dar ao invés de receber apoio, pois é ele quem tem que estar pronto a dar amparo às dúvidas dos outros, intervindo na resolução de diferentes situações, mesmo sentindo-se despreparado. Isto não é fácil para ele que até a poucos dias, podia contar com certa proteção que o papel de aluno lhe conferia, pois, a professora o resguardava de incertezas, dúvidas e medos que podia sentir ${ }^{(8)}$.

O iniciante vai tomando decisões em função dos resultados de suas avaliações que redirecionam seu agir, numa busca contínua de não permitir que nada fuja a seu controle o que marcaria sua imperícia. Esses esforços nos remetem a um terceiro momento: reconhecendo no poder um passaporte para cuidar, pois, conforme está fazendo este balanço, suas ações indicam que está buscando formas de selar sua identidade na interação poder-cuidar e expandindo projetos de realização. Assim, para firmar sua identidade, o enfermeiro recém-formado quer assumir responsabilidades, sentir-se como eixo, ser 
percebido como importante e necessário, denunciando sua opção: a objeção ao exercício da liberdade de ser, optando por uma estratégia paliativa de ter, na perícia em "dar conta de tudo", um substitutivo para sua inabilidade criativa(8).

Portanto, conclui-se que não há um estilo ideal de liderança a ser adotado, podendo este variar conforme a situação e os liderados. É desvelado que ao assumir a liderança os egressos de enfermagem por sentirem-se despreparados para o exercício, acabam assumindo postura centralizadora, com um estilo de liderança autocrático, não sendo considerado o melhor estilo a ser adotado, pois, este dificulta o trabalho em equipe e o desenvolvimento do processo de trabalho.

O outro tema, Exercício da Liderança, desvela a percepção do aluno de graduação em enfermagem enquanto sua vivência prática de Liderança. As unidades significativas resgatadas nos discursos como: Percepção da Prática da Liderança, No exercício da Liderança, Relacionamento Profissional, Supervisão de Enfermagem e Aprendizagem da Liderança permitiram a proposição desse tema.

A Percepção da Prática da Liderança é desvelada após a vivência prática nos estágios curriculares Relatam que alguns campos de estágio os levaram a perceber que liderança é uma ação participativa, na qual o líder respeita a função de cada liderado e toma decisões que serão benéficas para a equipe.

[...] passei em alguns campos de estagio e percebi que liderança é uma ação em conjunto, entre enfermeiro e auxiliares [...] tem que ser uma ação em conjunto [...] líder é aquele que sabe trabalhar junto, que sabe ouvir a equipe... chegando num consenso sobre a maneira que seria melhor para equipe tanto no trabalho, como as funções de cada um $[\ldots](I I-1)$.

O acadêmico considera que a vivência prática da liderança em diversos campos de estágio levou a percepção que liderança diferencia-se do que é idealizado na teoria.

[...] liderança na teoria é muito bonita [...] bem diferente do que tenho observado na prática durante os estágios [...] nos vários campos que passei [...] (III-1).

Contribuindo com este aspecto há necessidade de que o enfermeiro docente conheça os problemas vivenciados na prática assistencial, de modo que reflita, analise e proponha alternativas de intervenção que contribuam para modificar a situação do exercício profissional(9).

A Integração Docente Assistencial (IDA) pode contribuir para que os docentes superem a dicotomia entre a teoria e a prática, devido a sua maior aproximação com campo prático. Como conseqüências, possivelmente, terão ainda melhores preparo técnico e conhecimento da realidade ${ }^{(10)}$.

Apesar do reconhecimento das possibilidades de IDA no âmbito da enfermagem, entende-se que a escola tem dado pouca importância ao seu papel transformador na educação e na prática profissional ${ }^{(9)}$.

As falas dos sujeitos desvelam uma dissociação da prática com a teoria, enfatizando que a teoria é diferente da prática.
A IDA é de grande importância para promoção do processo de aprendizagem. As DCNS ressaltam ser necessária à formação de profissional com senso crítico, capaz de resolver problemas e com competência de liderança, muitas vezes esse exercício no mundo acadêmico, torna-se impossibilitado pela falta de integração docente assistencial. Na realidade dos sujeitos de pesquisa, por tratar-se de primeira turma do curso de graduação em enfermagem fica explícito, pelos depoimentos, a falta de integração dos serviços de saúde com a universidade, a qual encontrou durante o estágio, dificuldade para essa integração. Os fatores que influenciaram foram: as políticas das instituições de saúde e a falta de planejamento para integração docente assistencial do curso de graduação em estudo.

Portanto, para vencer os desafios propostos e implementar o novo na formação do enfermeiro, é necessário desvestir a roupa velha da dominação interessada no desgaste do trabaIho da enfermagem. A ocupação dos espaços deve ser planejada, realizada e avaliada por profissionais competentes na dimensão ética, técnica, estética e política, comprometida socialmente com o exercício da cidadania. O enfermeiro pretendido constrói a cada instante, juntamente com os professores e profissionais do campo de ação, a história da enfermagem ${ }^{(3)}$.

Outra unidade significativa que contribuiu para a proposição do tema é: No Exercício da Liderança, a qual revela, através das falas, a observação da atuação do enfermeiro como líder ficando evidente que existe uma dificuldade do enfermeiro em exercer a função de líder, sendo atribuída à falta de conhecimento teórico do enfermeiro. O conhecimento é importante para o exercício da liderança.

[...] observo que às vezes os enfermeiros não conseguem liderar uma equipe porque não tem conhecimento teórico [...] (III-4).

Ao transportar-se para o cenário da enfermagem brasileira, compete ao enfermeiro o gerenciamento da assistência de enfermagem prestada ao paciente, sendo sua ação direcionada para o desenvolvimento de atividades administrativas, assistenciais, educativas e de pesquisa com vistas ao aprimoramento da prática profissional. O enfermeiro desenvolve uma gerência mais orientada para as necessidades do serviço, para o cumprimento de regulamentos, normas e tarefas reproduzindo o que é preconizado pela organização e por outros profissionais, principalmente a equipe médica. Esta forma de gerenciar contribui muitas vezes para o não atendimento das necessidades do paciente e principalmente gera insatisfações nos membros da equipe de enfermagem. Essa realidade vem suscitando inquietações e questionamentos nos enfermeiros de instituições de ensino e serviço ${ }^{(11)}$.

Desta maneira cabe a educação fornecer, de algum modo, os mapas de um mundo complexo e constantemente agitado. Para isso a educação deverá ser organizada em torno de quatro aprendizagens, que se constituirão para cada individuo, ao longo de suas vidas nos quatro pilares do conhecimento: aprender a conhecer isto é adquirir os instrumentos da compreensão; aprender a fazer, para poder agir sobre o meio envolvente; aprender a viver junto, a fim de participar 
e a cooperar com os outros em todas as atividades humanas, finalmente aprender a ser, via essencial que integra os três precedentes $^{(12)}$.

A competência resulta da combinação dos conhecimentos. As falas dos sujeitos desvelaram a importância do conhecimento teórico para o desenvolvimento da liderança, para uma liderança eficaz, para um líder competente é necessária, a combinação do aprender a conhecer, aprender fazer, aprender viver junto e aprender a ser. A falta da vivência prática do fenômeno liderança é fator contribuidor para que os sujeitos não mencionem a necessidade do desenvolvimento da competência baseada nos quatro pilares.

Desta forma, concluir um curso de graduação significa momento de grande realização e satisfação pessoal, mas muitas vezes é motivo de grande angústia e ansiedade. Normalmente, o primeiro emprego é um desafio que acompanha o profissional em seus primeiros meses de exercício profissional. $\mathrm{O}$ enfermeiro recém-graduado enfrenta esse desafio com muita insegurança e receios, pois encontra inúmeras dificuldades que se iniciam com o processo admissional e continuam com a sua adaptação ao serviço de saúde ${ }^{(13)}$.

Supervisão em enfermagem contribuiu como unidade significativa para a proposição do tema. É desvelada por um único depoimento e é compreendida como função exclusiva do enfermeiro e tem como prerrogativa determinar as funções da equipe de enfermagem.

[...] O enfermeiro tem que determinar certas funções para os auxiliares e técnicos [...] e vai supervisionar o que eles [...] estão fazendo [...] (IV-2).

Desta forma, o entendimento das relações existentes entre políticas de saúde e o trabalho da enfermeira, são importantes no desempenho da função supervisão, pois esta é inerente a qualquer processo de trabalho e realiza-se em bases coletivas $^{(14)}$.

O principal objetivo da supervisão é elevar a qualidade dos serviços prestados e para contribuir para o aperfeiçoamento do pessoal e avaliar o seu desempenho, visando à promoção da saúde, melhor recuperação do cliente e ao bom funcionamento do estabelecimento de saúde ${ }^{(15)}$.

A proposição do tema contou também com a unidade significativa; Aprendizagem da Liderança, os depoimentos desvelaram o fenômeno liderança como um processo de aprendizagem constante, passível de ser aprendida com a interação profissional e relações sociais, de grande importância para o desenvolvimento do processo de trabalho da enfermagem.

[...] aprendendo com a equipe, com os auxiliares que trabalharem comigo, porque vejo que eles têm muita experiência [...] (III-5).

[...] é muito importante gente saber liderar e aonde é que existe $O^{\prime \prime} X$ "da questão, porque a faculdade não te dá pratica para isso, você aprende na teoria, mas na prática! A prática você não tem no estagio de ser líder, você vai ter prática no dia-a-dia, para aprender, então acho que deveríamos ter a oportunidade de ter a prática para aprender![...] vou saber como liderar no meu campo de trabalho, que vou saber como liderar [...] (XIV-3).

As instituições formadoras apresentam deficiências em preparar o aluno para assumir a função de liderança, constata-se a ocorrência de frustração e desencantamento do enfermeiro com relação a essa atividade, como também uma desilusão por parte do empregador, que alimenta a expectativa de contratar um profissional apto a atuar com capacidade de liderança ${ }^{(2)}$.

A LDB trouxe novas responsabilidades para as instituições de ensino superior, seus docentes, discentes e sociedade, ao permitir a formação de diferentes perfis profissionais de acordo com cada escola. Por serem conhecedores da realidade social local e do mercado de trabalho, as instituições têm liberdade para definir parte considerável de seus currículos plenos $^{(16)}$.

Essa autonomia das escolas deve ser questionada, já que elas possuem a opção de escolher conteúdos que atendam somente às necessidades momentâneas do mercado de trabaIho. Ao formar profissionais voltados exclusivamente ao mercado de trabalho, corre-se o risco de que a escola impressione a sociedade com a máscara da excelência. Porém, em poucos anos, as mudanças tecnológicas acabam por tornar, esses profissionais, obsoletos e descartáveis ${ }^{(16)}$.

Os Cursos de Graduação em Enfermagem devem estar com o ensino voltado para a formação de profissionais capazes de promover melhoria social, não se restringindo apenas a estar formando profissionais para atender as necessidades temporárias do mercado. Para isso, a LDB fala no ensino por competências, capaz de formar profissional crítico-reflexivo, as quais o enfermeiro não acaba o processo de formação ao sair da universidade, o processo educacional é permanente.

As DCNS destacam a Liderança como uma das principais competências a ser adquirida pelo enfermeiro. É salientado que durante o processo de aprendizagem da liderança na graduação em enfermagem, em experiência vivenciada de liderança os fez refletir qual o estilo de liderança seria melhor a ser adotado, sendo necessário considerar o trabalho em equipe para a adoção de um estilo eficiente para o desenvolvimento do trabalho e que o processo de aprendizagem trata-se de um contínuo.

[...] tive uma experiência assim, como aluna, teve uma professora, que fez um trabalho sobre liderança com a gente, e ela escolheu um líder em cada grupo e disse: Vocês vão dar uma tarefa para cada um da equipe, eles vão ter que dar palestras! E, tinha que montar uma palestra, então, eu comecei a pedir para cada um quem queria dar palestra: Fulano, você quer? Não, Fulano, você quer? Não! Ninguém quis. Foi uma experiência que: eu perdi sono, começou [...] daí eu parei e pensei? Que tipo de Líder eu vou ser? Então, [...] parei e pensei [...] eu vou fazer tudo?... cheguei na professora e falei: Professora vou poder escolher? Ela falou: Você como líder é para escolher, e não, vai apresentar a palestra![...] líder, algumas vezes você vai ter que ser 
duro! Vai ter que ser exigente! Porque você também vai ter que puxar um pouco as rédias! é também ser paternalista, porque senão as coisas desanda, , você tem que mostrar o trabalho em conjunto[...] (XV-3)

Corroborando este aspecto, ensinar é definido como facilitar a aprendizagem, criando condições para que o outro, a partir dele próprio aprenda e cresça. O indivíduo é o centro da aprendizagem que se processa em função do desenvolvimento e interesse do aluno. Coloca-se assim uma ênfase nas relações interpessoais e no crescimento pessoal que delas resultam ${ }^{(17)}$.

Desta forma, a experiência vivida pelo acadêmico colabora para a construção do processo de aprendizagem e define como será a forma de exercitar a liderança.

\section{CONCLUSÃO}

Ao desvelar a essência do fenômeno pesquisado, os depoimentos revelam convergências, divergências e idiossincrasias que permitem a compreensão da percepção dos alunos sobre a liderança e sua prática profissional de liderança em enfermagem.

As diferentes formas em que a liderança acontece, no tema Estilos de Liderança, são formas mutantes do fenômeno e revelam-se como significados transituacionais, influenciado pela política institucional, pelo ensino e liderados. Entende-se como processo dinâmico à liderança e o estilo adotado como forma de conduzir uma equipe, não existindo um estilo ideal de liderança.
É compreendido que o bom líder ampara os funcionários, promove escuta e não age apenas de forma autoritária. Sua postura deve ser de compartilhamento com os liderados para o desenvolvimento de um bom relacionamento.

No ensino, o estilo de liderança passou a ser discutido quando abordou as formas participativas de gerenciamento de pessoal.

Outro tema destacado foi Exercício da Liderança, sendo enfatizada a dissociação da teoria e da prática da liderança. Compreendido que, para ocorrer o fenômeno, é necessário esforços das instituições educacionais e de saúde, com o objetivo de formar profissionais com pensamento crítico-reflexivo, capaz de promover mudanças sociais e que atenda as necessidades da atenção à saúde. A compreensão do tema foi possível após a vivência prática dos estágios curriculares, sendo a liderança compreendida como ação participativa.

As falas dos sujeitos desvelam a dissociação da teoria e prática. Neste sentido, é importante destacar que a interação docente assistencial é de grande relevância para a aprendizagem da liderança. A falta de integração dificulta o exercício da liderança no mundo acadêmico. Na realidade dos sujeitos de pesquisa, que são alunos da primeira turma do curso de graduação em enfermagem da universidade em estudo, esta situação é relevante, pois a integração docente assistencial ainda não está construída.

Considerando a abrangência do fenômeno liderança, podem ser contempladas outras perspectivas e novas possibilidades dado os ilimitados horizontes que habitam os seres no mundo.

\section{REFERÊNCIAS}

1. Chiavenato I. Introdução à Teoria Geral da Administração. 3 ed. São Paulo: Makron Books; 1994.

2. Simões ALA, Fávero N. Aprendizagem da liderança: opinião de enfermeiros sobre a formação acadêmica. Rev Latino-Am Enferm 2000;8(3):91-6.

3. Ito EE, Peres AM, Takahashi RT, Leite MMJ. O ensino de enfermagem e as diretrizes curriculares nacionais: utopia x realidade. Rev Esc Enferm USP 2006;40(4):570-5.

4. Higa EFR, Trevizan MA. Os estilos de liderança idealizados pelos enfermeiros. Rev Latino-Am Enferm 2005;13(1):59-64

5. Pires RP. Formação de competências na interface estágio extracurricular e início da atuação profissional como enfermeiro. São Paulo. Dissertação [Mestrado em Enfermagem] - Escola de Enfermagem da USP; 2006.

6. Ministério da Educação (Brasil). Portaria $n^{\circ}$. 1518, de 14 de junho de 2000. Dispõe sobre as diretrizes curriculares do curso de graduação em enfermagem. Diário Oficial da União 30 jun 2000;Seção 1.

7. Kurcgant P. A liderança na administração do pessoal de enfermagem segundo a percepção de enfermeiras que vivenciam esta pratica em hospital. São Paulo. Tese
[Livre-docência em Enfermagem ] - Escola de Enfermagem da USP; 1992.

8. Matheus MCC, Ide CAC, Ângelo M. Reflexiones acerca de los actores coadyuvantes de la experiencia de la enfermera recien formada. Cienc Enferm 2006;12(2):45-51.

9. Beccaria LM, Trevizan MA, Janucci MZ. Integração docente-assistencial entre um curso de enfermagem e um hospital de ensino: concepção do processo sob a ótica de docentes, alunos e enfermeiros. Arq Ciênc Saúde 2006;13(3):137-145.

10. Shimizu HE. A percepção de docentes do curso de graduação em enfermagem e obstetrícia de uma universidade pública federal sobre a integração docente assistencial. Rev Latino-Am Enferm 1999;7(5): 51-58.

11. Galvao CM, Trevizan MA, Sawada NO. A liderança do enfermeiro no século XXI: algumas considerações. Rev Esc Enferm USP 1998;32(4):302-6.

12. Gabrielli JMW. Formação do enfermeiro: buracos negros e ponto de luz. Ribeirão Preto. Tese [Doutorado em Enfermagem] - Escola de Enfermagem da USP; 2004.

13. 13.Dias AO, Guariente MHDM, Belei RA. O enfermeiro recém-graduado e o primeiro emprego. Percepções da 
formação na graduação e da atuação profissional. Arq Ciênc Saúde Unipar 2004;8(1):19-24.

14. Arratia Figueroa A. Livre vontade do usuário frente à educação em saúde. Texto \& Contexto Enferm 1997;6(3):131-47

15. Brasil. Decreto n. ${ }^{\circ} 94.406$, de 08 de junho de 1987. Regulamenta a lei no 7.498 , de 25 de junho de 1986, que dispõe sobre o Exercício da enfermagem, e dá outras providências.
Diário Oficial da União 09 jun de 1987;125(10):8853-8855.

16. Peres AM. Competências gerenciais do enfermeiro: relação da expectativa da instituição formadora e do mercado de trabalho. São Paulo. Tese [Doutorado em Enfermagem] - Escola de Enfermagem da USP; 2006.

17. Stacciarini JMR, Esperidião E. Repensando estratégias de ensino no processo de aprendizagem. Rev Latino-Am Enferm 1999;7(5):59-66. 